\title{
Characterization of human UGT2A3 expression using a prepared specific antibody against UGT2A3
}

\section{Gotoh-Saito, Saki}

2019-08

Gotoh-Saito , S , Abe , T , Furukawa , Y , Oda , S , Yokoi , T , Finel , M , Hatakeyama , M , Fukami , T \& Nakajima , M 2019 , ' Characterization of human UGT2A3 expression using a prepared specific antibody against UGT2A3 ' , Drug Metabolism and Pharmacokinetics, vol. 34 , no. 4 , pp. 280-286 . https://doi.org/10.1016/j.dmpk.2019.05.001

http://hdl.handle.net/10138/318020

https://doi.org/10.1016/j.dmpk.2019.05.001

cc_by_nc_nd

acceptedVersion

Downloaded from Helda, University of Helsinki institutional repository.

This is an electronic reprint of the original article.

This reprint may differ from the original in pagination and typographic detail.

Please cite the original version. 


\section{Characterization of human UGT2A3 expression using a prepared specific antibody against UGT2A3}

Saki Gotoh-Saito ${ }^{\mathrm{a}}$, Takayuki Abe ${ }^{\mathrm{a}}$, Yoichi Furukawa ${ }^{\mathrm{a}}$, Shingo Oda ${ }^{\mathrm{a}}$, Tsuyoshi Yokoi ${ }^{\mathrm{a}}$, Moshe Finel $^{\mathrm{b}}$, Masahiko Hatakeyama ${ }^{\mathrm{c}}$, Tatsuki Fukami ${ }^{\mathrm{a}, \mathrm{d}}$, Miki Nakajima ${ }^{\mathrm{a}, \mathrm{d}}$

${ }^{a}$ Drug Metabolism and Toxicology, Faculty of Pharmaceutical Sciences, Kanazawa University, Kakuma-machi, Kanazawa 920-1192, Japan

${ }^{\mathrm{b}}$ Division of Pharmaceutical Chemistry and Technology, Faculty of Pharmacy, University of Helsinki, Helsinki, Finland

${ }^{\mathrm{C}}$ CLEA Japan, Kitayama 4839-23, Fujinomiya, Shizuoka 418-0112, Japan

${ }^{\mathrm{d}}$ WPI Nano Life Science Institute, Kanazawa University, Kakuma-machi, Kanazawa 920-1192, Japan

\section{Corresponding author}

Miki Nakajima, Ph.D.

Drug Metabolism and Toxicology, Division of Pharmaceutical Sciences, Graduate School of Medical Science, Kanazawa University, Kakuma-machi, Kanazawa 920-1192, Japan. E-mail: nmiki@p.kanazawa-u.ac.jp Tel: +81-76-234-4408

\section{Present address}

Shingo Oda and Tsuyoshi Yokoi

Department of Drug Safety Sciences, Division of Clinical Pharmacology, Nagoya University Graduate School of Medicine, 65 Tsurumai-cho, Showa-ku, Nagoya, 466-8550, Japan 


\begin{abstract}
UDP-Glucuronosyltransferase (UGT) 2A3 belongs to a UGT superfamily of phase II drugmetabolizing enzymes that catalyzes the glucuronidation of many endobiotics and xenobiotics. Previous studies have demonstrated that UGT2A3 is expressed in the human liver, small intestine, and kidney at the mRNA level; however, its protein expression has not been determined. Evaluation of the protein expression of UGT2A3 would be useful to determine its role at the tissue level. In this study, we prepared a specific antibody against human UGT2A3 and evaluated the relative expression of UGT2A3 in the human liver, small intestine, and kidney. Western blot analysis indicated that this antibody is specific to UGT2A3 because it did not cross-react with other human UGT isoforms or rodent UGTs. UGT2A3 expression in the human small intestine was higher than that in the liver and kidney. Via treatment with endoglycosidase, it was clearly demonstrated that UGT2A3 was $N$-glycosylated. UGT2A3 protein levels were significantly correlated with UGT2A3 mRNA levels in a panel of 28 human liver samples $(r=0.64, p<0.001)$. In conclusion, we successfully prepared a specific antibody against UGT2A3. This antibody would be useful to evaluate the physiological, pharmacological, and toxicological roles of UGT2A3 in human tissues.
\end{abstract}

\title{
Keywords
}

UGT2A3; Human liver microsomes; Human intestine microsomes; Glycosylation; Specific antibody 


\begin{abstract}
Abbreviations
Endo H, Endoglycosidase H; ER, endoplasmic reticulum; LC-MS/MS, liquid chromatography tandem-mass spectrometry; PAGE, polyacrylamide gel electrophoresis; PNGase F, peptide: $N$ glycosidase F; SNP, single nucleotide polymorphism; UDPGA, uridine-5' -diphosphate glucuronic acid; UGT, UDP-glucuronosyltransferase; UTR, untranslated region
\end{abstract}




\section{Introduction}

UDP-Glucuronosyltransferases (UGTs) are the major phase II drug-metabolizing enzymes that catalyze glucuronidation of a wide variety of endogenous and exogenous lipophilic substances, including steroid hormones, dietary chemicals, drugs, carcinogens, and other various environmental chemicals [1-3]. Glucuronidation is a step to increase the watersolubility of these compounds and facilitate their excretion into bile or urine. In humans, approximately $40-70 \%$ of clinically used drugs are subjected to glucuronidation [4].

Human UGTs are classified into two distinct gene families, UGT1 and UGT2, which are subdivided into the UGT1A (1A1, 1A3, 1A4, 1A5, 1A6, 1A7, 1A8, 1A9, and 1A10), UGT2A (2A1, 2A2, and 2A3), and UGT2B (2B4, 2B7, 2B10, 2B11, 2B15, 2B17, and 2B28) subfamilies on the basis of gene structure and amino acid sequence homology $[5,6]$. The UGT1A gene, located on chromosome $2 \mathrm{q} 37$, encodes nine functional enzymes by alternative splicing of unique exon 1 to the common exons 2-5 by exon sharing [7]. The UGT2A and $2 B$ genes, located on chromosome 4q13, encode three and seven functional enzymes, respectively [6]. UGT2A1 and 2A2 are encoded by alternative splicing of the unique exon 1 to the common exons 2-6, likely UGT1A family members. Moreover, UGT2A3 and 2B isoforms are each produced from a unique gene [6]. The UGT1A and 2B subfamilies have been extensively studied and functionally characterized, while little has been reported on the expression and function of the three members of the UGT2A subfamily.

UGT2A3 was originally identified through screening of a guinea pig (Cavia porcellus) liver cDNA library [8]. UGT2A3 cDNA was subsequently cloned from the human liver, and then employed to prepare recombinant protein [9]. The expression of UGT2A3 mRNA has been detected in the human liver, small intestine, colon, adipose tissue, kidney, trachea, larynx, tonsil, lung, and nasal tissues [9-11]. In contrast, thus far detection of UGT2A3 protein has not previously been reported in any human tissue. The lack of a specific antibody against 
UGT2A3 is one of the reasons that it has not been analyzed. As poor correlations between the mRNA and protein levels were previously observed for some UGT isoforms [12, 13], the determination of protein levels would be necessary for the functional analysis. In recent studies, liquid chromatography tandem-mass spectrometry (LC-MS/MS) analysis has been employed to quantify the absolute abundances of target proteins. However, this analysis is not widely used to date because highly sensitive and expensive LC-MS/MS instruments as well as highly trained and skilled staff are required. In contrast, Western blot analysis is widely used due to its convenience and low running cost. For such an analysis, antibodies that selectively react with the target protein are required. In the present study, we sought to prepare a monoclonal antibody that specifically recognizes human UGT2A3. Using the prepared antibody, we evaluated the tissue localization and interindividual variability in UGT2A3 protein expression in human tissues. 


\section{Materials and Methods}

\section{Materials}

Recombinant human UGT1As (1A1, 1A3, 1A4, 1A6, 1A7, 1A8, 1A9, and 1A10), human UGT2Bs (2B4, 2B7, 2B10, 2B15, and 2B17) expressed in baculovirus-infected insect cells (Supersomes), pooled human liver microsomes (50-donors), and pooled human small intestinal microsomes (7-donors) were purchased from Corning (Corning, NY). Pooled human kidney microsomes (6-donors) were purchased from Tissue Transformation Technologies (Edison, NJ). Pooled mouse or rat liver microsomes (8-week-old C57BL/6 mice or 7-week-old Sprague-Dawley rats, $\mathrm{n}=3$ for each sex) were prepared as previously described [14]. Human liver samples from 28 donors were supplied by the National Disease Research Interchange (Philadelphia, PA) through the Human and Animal Bridging Research Organization (Chiba, Japan). The information of the donors is shown in Supplemental Table. Microsomes were prepared as previously described [14]. The use of the human livers was approved by the ethics committees of Kanazawa University (Kanazawa, Japan).

Endoglycosidase H (Endo H), peptide: $N$-glycosidase F (PNGaseF) and $O$-glycosidase were purchased from New England Biolabs (Ipswich, MA, USA). Restriction endonucleases and DNA-modifying enzymes were obtained from Takara (Shiga, Japan). All reagents were of the highest grade that was commercially available.

\section{Preparation of monoclonal antibody against human UGT2A3}

The selection of the antigenic peptide, peptide synthesis, and keyhole limpet hemocyanin conjugation was performed by Biogate (Gifu, Japan). The antigenic peptide sequence was designed as follows. Hydrophilicity was evaluated by the method of Hopp and Woods [15]. Secondary structure was evaluated by the methods of Chou and Fasman [16] and Garnier et al. [17] using GENETYX-MAC software (Software Development, Tokyo, Japan). Surface 
probability was evaluated by the method of Emini et al. [18]. Antigenicity was evaluated by the methods of Welling et al. [19] and Parker et al. [20] using original software. The designed peptide sequence was subjected to BLASTP search (http://www.ncbi.nlm.nih.gov/blast/) to screen its homology with known protein sequences. Based on these evaluations, the sequence HMPQDRTEENEIFVDLALNVLPGLSTWQS, which corresponds to residues 78 to 106 of human UGT2A3, was identified as a candidate peptide. At the $\mathrm{N}$ terminus of the synthesized peptide, a cysteine residue was added to facilitate conjugation to the carrier protein, keyhole limpet hemocyanin. A mouse monoclonal antibody against the peptide was prepared by CLEA Japan (Tokyo, Japan) using a standard protocol. The reactivity and specificity of hybridomas producing the antibodies were evaluated by Western blot analysis using a recombinant human UGT2A3 protein subsequently described. A clone that specifically reacted with UGT2A3 was expanded by intraperitoneal injection into mineral oil-primed mice. Monoclonal antibodies from mouse ascitic fluids were partially purified by precipitation with $33 \%$ ammonium sulfate.

\section{Cell culture}

Human hepatocellular carcinoma HepG2 or Huh-7 cells and human epithelial colorectal adenocarcinoma Caco-2 or LS180 cells were maintained in Dulbecco's modified Eagle's medium (DMEM) supplemented with 10\% fetal bovine serum (FBS), 2 mM L-glutamine, 100 units $/ \mathrm{mL}$ penicillin and $100 \mu \mathrm{g} / \mathrm{mL}$ streptomycin in an atmosphere of $5 \% \mathrm{CO}_{2}$ at $37{ }^{\circ} \mathrm{C}$.

\section{Recombinant UGT2As expressed in baculovirus-infected Sf9 cells}

Recombinant human UGT2A1, UGT2A2 and UGT2A3 were constructed using a Bac-toBac Baculovirus Expression System (Invitrogen) according to the manufacturer's instructions. pFastBac vectors that contained human UGT2A1, UGT2A2 or UGT2A3 coding sequences tagged with a polyhistidine sequence at the C-terminus were previously constructed [9]. Each 
vector was transformed into DH10Bac-competent cells, followed by transposition of the inserts into bacmid DNA. Spodoptera frugiperda Sf9 cells were grown in Sf-900 II SFM that contained $10 \%$ fetal bovine serum at $27^{\circ} \mathrm{C}$ without $\mathrm{CO}_{2}$. The recombinant bacmid DNA was transfected into Sf9 cells with Cellfectin Reagent (Invitrogen), and the virus was harvested by collecting the cell culture medium at $72 \mathrm{~h}$ post transfection. The cells were washed with icecold PBS and suspended in TGE buffer [10 mM Tris-HCl (pH 7.4), 20\% glycerol, and $1 \mathrm{mM}$ EDTA], then subjected to repeated freeze-thaw cycles. The suspensions were homogenized with a microhomogenizer. The expression of UGT2A proteins was confirmed by Western blot analysis using anti-His tag antibody (data not shown).

\section{Recombinant UGT2A3 expressed in Huh-7 cells}

The full-length human UGT2A3 cDNA was amplified using a primer pair, 5'AGAGTCGGATCCATGAGGTCTGACAAGTCAGCTT -3' and 5'CGTGTCCTCGAGCTATTCCCTCTTTTCTATCTTT -3', and pFastBac/ UGT2A3 was used as a template. The amplicon was subcloned into the $B a m \mathrm{H} \mathrm{I} / X h o$ I sites of pcDNA3.1/Hygro(+) (Thermo Fisher Scientific, MA, USA). The constructed pcDNA3.1/Hygro(+)/hUGT2A3 plasmid was transfected into Huh-7 cells using Lipofectamine 2000 (Invitrogen). After 48 h, total cell homogenates were prepared by a previously described method [21]. Briefly, the cells were suspended in Tris-buffered saline [25 mM Tris-HCl buffer ( $\mathrm{pH} 7.4), 138 \mathrm{mM} \mathrm{NaCl}$, and $2.7 \mathrm{mM} \mathrm{KCl}$ ] and disrupted by freezethaw cycles. The suspensions were homogenized with a microhomogenizer. The protein concentrations of the homogenates were determined according to Bradford [22].

\section{Preparation of microsomes from cultured cells}

Cells were scraped, pelleted and resuspended in ice-cold homogenization buffer $[0.1 \mathrm{M}$ 
Tris- $\mathrm{HCl}(\mathrm{pH} 7.4), 0.1 \mathrm{M} \mathrm{KCl}$, and $1 \mathrm{mM}$ EDTA]. The suspension was homogenized using a $1.5 \mathrm{~mL}$ tube size disposable homogenizer, followed by centrifugation at 9,000 $\mathrm{g}$ for $15 \mathrm{~min}$ at $4{ }^{\circ} \mathrm{C}$. The supernatant was centrifuged at $105,000 \mathrm{~g}$ for $60 \mathrm{~min}$ at $4{ }^{\circ} \mathrm{C}$. The pellet was resuspended in ice-cold TGE buffer and sonicated. The prepared microsomes were stored frozen at $-80{ }^{\circ} \mathrm{C}$ until use.

\section{SDS-PAGE and Western blot analysis}

Proteins were separated on a 10\% SDS-PAGE and transferred onto Protran nitrocellulose membranes (Whatman GmbH, Dassel, Germany). These membranes were blocked with Odyssey blocking buffer (LI-COR Biosciences, Lincoln, NE), incubated with anti-human UGT2A3 monoclonal antibody, washed with PBS-T (3.2 $\mathrm{mM} \mathrm{Na}_{2} \mathrm{HPO}_{4}, 0.5 \mathrm{mM} \mathrm{KH}_{2} \mathrm{PO}_{4}$, $1.3 \mathrm{mM} \mathrm{KCl}, 135 \mathrm{mM} \mathrm{NaCl}, 0.05 \%$ Tween20, $\mathrm{pH}$ 7.4), and then incubated with IRDye 680LT Goat anti-mouse IgG secondary antibody. The bands were visualized and their densities were quantified with an Odyssey Infrared Imaging system (LI-COR Biosciences) within the range showing linearity of the band density. UGT2A3 protein levels are expressed as the levels relative to that of the lowest sample, after the normalization with a control sample. The data are represented as the means \pm SD of three independent determinations.

\section{Treatment of UGT2A3 protein with Endo H, PNGase F or $O$-glycosidase}

Human liver or intestinal microsomes and recombinant UGT2A3 expressed in Sf9 cells or Huh-7 cells were adjusted to a $2 \mathrm{mg} / \mathrm{mL}$ protein concentration with a denaturing buffer in a final concentration of $0.5 \%$ SDS and $40 \mathrm{mM}$ DTT and were denatured at $100^{\circ} \mathrm{C}$ for $10 \mathrm{~min}$. The denatured proteins $(20 \mu \mathrm{g})$ were incubated with $250 \mathrm{U}$ of Endo $\mathrm{H}$ in $50 \mathrm{mM}$ sodium acetate buffer ( $\mathrm{pH}$ 6.0), $500 \mathrm{U}$ of PNGase F in $50 \mathrm{mM}$ sodium phosphate buffer (pH 7.5) with $0.1 \% \mathrm{NP}-40$ or $40,000 \mathrm{U}$ of $O$-glycosidase in $50 \mathrm{mM}$ sodium phosphate buffer (pH 6.0) with 
$0.1 \% \mathrm{NP}-40$ in a final volume of $20 \mu \mathrm{L}$ at $37^{\circ} \mathrm{C}$ for $1 \mathrm{~h}$; the samples were then subjected to SDS-PAGE and Western blot analysis.

\section{qRT-PCR}

Total RNA was extracted using RNAiso Plus (Takara) to synthesize cDNA with ReverTra Ace (Toyobo, Osaka, Japan). Real-time RT-PCR was performed using the Mx3000P (Stratagene, La Jolla, CA) with the MxPro QPCR software. The following PCR primers were used with the SYBR Premix Ex Taq solution (Takara): 5'-ATGAGGTCTGACAAGTC AGCTT-3' and 5'-TCAAAATCCCAATATGTTCG-3' for human UGT2A3 and 5'CCAGGGCTGCTTTTAACTC-3' and 5'- GCTCCCCCCTGCAAATGA-3' for human GAPDH. The PCR conditions were as follows: after an initial denaturation at $95^{\circ} \mathrm{C}$ for $60 \mathrm{~s}$, amplification was performed by denaturation at $94^{\circ} \mathrm{C}$ for $5 \mathrm{~s}$ followed by annealing/extension at $64^{\circ} \mathrm{C}$ for $30 \mathrm{~s}$ for 40 cycles. The UGT2A3 mRNA levels were normalized to the GAPDH mRNA levels. UGT2A3 mRNA levels are expressed as the levels relative to that of the lowest sample. The data are represented as the means $\pm \mathrm{SD}$ of triplicate determinations.

\section{Statistical analyses}

The relationship between UGT2A3 mRNA and protein was investigated using the Spearman's product-moment correlation coefficient. Statistical analyses were performed using GraphPad Prism5 at a significance level of $p<0.05$. 


\section{Results}

\section{Specificity of the human UGT2A3 antibody}

Human UGTs within the same family show high amino acid sequence homology (as high as $94 \%$ for some isoforms). The amino acid sequence of UGT2A3 is most similar to that of UGT2A2 (62\% amino acid sequence identity) (Table 1). It can be emphasized that the identity of residues 78 to 106 of human UGT2A3, which was used as an antigen to produce the monoclonal antibody, with other UGTs was $34 \%$ at most (Table 1). To investigate the specificity of the prepared antibody, we performed Western blot analysis using human recombinant UGT1A, UGT2B and UGT2A proteins expressed in baculovirus-infected insect cells. As shown in Fig. 1A, this antibody only reacted with UGT2A3 protein.

\section{Evaluation of UGT2A3 protein expression in human and rodent tissues}

When microsomes from the human liver, kidney and small intestine were subjected to Western blot analysis using the new antibody against UGT2A3, a band was detected at a little more higherにすべきだったか than $50 \mathrm{kDa}$ in all these microsomes (Fig. 1B). Following cleavage of the signal peptide, the predicted molecular weight of human UGT2A3 protein is $57.7 \mathrm{kDa}$. The faster migration than theoretical molecular weight might be due to high binding of SDS to UGT2A3 protein, because it has been reported that hydrophobic proteins such as transmembrane proteins bind higher amounts of SDS than hydrophilic ones, and therefore they migrate faster in SDS-PAGE [23].

The UGT2A3 protein level was highest in the intestine, followed by the kidney and then the liver (Fig. 1B). The UGT2A3 protein level in the liver was only about $15 \%$ the intestine expression level (Supplemental Figure). UGTs are known to be localized in the endoplasmic reticulum (ER) membrane. In accordance with this localization UGT2A3 was detected in the 
microsomal fraction, but not in the cytosolic fraction (Fig. 1C).

The amino acid sequence homology of the antigen peptide with rodent UGT2A3 was $31 \%$ at most (Table 2). When the liver and intestine microsomes from mice and rats were subjected to Western blot analyses, no bands were detected (Fig. 1D), indicating that the prepared antibody did not cross-react with rodent UGTs. Thus, this antibody is highly specific to the human UGT2A3.

\section{UGT2A3 protein expression in human cell lines}

The expression levels of UGT2A3 protein in human hepatocellular carcinoma-derived cells (Huh-7 cells and HepG2 cells) and epithelial colorectal adenocarcinoma-derived cells (LS180 cells and Caco-2 cells) were examined. The highest UGT2A3 expression was observed in LS180 cells, followed by Caco-2 cells (Fig. 1E). The expression levels in Huh-7 cells and HepG2 cells were substantially lower than those of the two colorectal cell lines. These results suggested that UGT2A3 is preferentially expressed in cell lines derived from the intestine rather than those derived from the liver.

\section{$N$-Glycosylation of human UGT2A3 protein}

The glycosylation status of UGT2A3 remains unknown. A search of asparagine-linked ( $N$-linked) glycosylation sites using a computational prediction tool, NetNGlyc 1.0 (http://www.cbs.dtu.dk/services/NetNGlyc/), revealed potential $N$-glycosylation sites at Asn131 and Asn-313 in UGT2A3. A search for $O$-linked glycosylation sites, using the prediction tool NetOGlyc 4.0 (http://www.cbs.dtu.dk/services/NetOGlyc/), predicted potential $O$ glycosylation sites at Thr-197 and Thr-200 (Fig. 2A). To examine whether UGT2A3 is indeed glycosylated, human liver microsomes (HLM), human intestine microsomes (HIM) and recombinant UGT2A3 in Sf9 cells were treated with the following endoglycosidases: a. Endo 
$\mathrm{H}$, which digests $N$-linked high-mannose carbohydrate side chains of glycoproteins; $\mathrm{b}$.

PNGase F, which catalyzes the cleavage of all $N$-linked oligosaccharides; c. $O$-glycosidase, which cleaves serine- or threonine-linked oligosaccharides. Cell lysates were then subjected to SDS-PAGE and Western blot analysis. Following the treatment with either Endo H or PNGase F of HLM and HIM, a single band of UGT2A3 at $50 \mathrm{kDa}$ was clearly shifted to a band that indicated faster mobility in SDS-PAGE. Recombinant 2A3 showed bands with larger molecular weight than endogenous UGT2A3, which could be attributable to the addition of the histidine tag and/or difference(s) in the glycosylation between insect cells and mammalian cells. Following treatments of the recombinant UGT2A3 with either Endo H or PNGase F, a new band with faster mobility appeared (Fig. 2B, upper and middle right panels). UGT2A3 transiently expressed in Huh-7 cells that showed the same mobility as endogenous UGT2A3 in HLM was also shifted by the treatment with PNGase F (Fig. 2B, middle right panel). These results suggest that UGT2A3 is $N$-glycosylated. In contrast, treatment with $O$ glycosidase did not change the mobility of UGT2A3 protein in HLM, HIM or Sf9 cells (Fig. 2B, lower panel). These results indicated that UGT2A3 undergoes post-translational $\mathrm{N}$ glycosylation. Thus, the prepared antibody might be useful for examining the function of UGT2A3 $N$-glycosylation.

\section{Interindividual variability of the UGT2A3 expression levels in the human liver}

We subsequently evaluated the relative expression levels of UGT2A3 protein and mRNA in a panel of 28 human livers by Western blot analysis and qRT-PCR. The variabilities in UGT2A3 protein and mRNA were 3-fold and 26-fold, respectively (Fig. 3A and 3B), indicating higher variability in the mRNA level than in the protein level. As shown in Fig. 3C, the UGT2A3 protein levels were significantly correlated with the UGT2A3 mRNA levels $(r=$ $0.64, p<0.001)$. 


\section{Discussion}

UGT2A3 is a relatively novel human UGT isoform, which was identified a decade ago [9]. Moreover, UGT2A3 is the only member of the UGT2A subfamily that was reported to express, at the mRNA level, in main drug metabolism tissues, namely liver, kidney and particularly the small intestine. By screening 81 structurally diverse glucuronidation substrates, it has been demonstrated that recombinant UGT2A3 expressed in baculovirusinfected insect cells catalyzed the glucuronidation of bile acids, although its activity was rather low [9]. UGT2A3 mRNA is expressed in the human liver, small intestine, colon, adipose tissue, trachea, larynx, and tonsil $[9,11]$ and is expressed at low levels in the lung and nasal tissues [10]. However, no papers have critically assessed UGT2A3 protein expression. In the present study, we prepared a specific antibody against human UGT2A3 and evaluated the UGT2A3 protein expression in the human liver, intestine, and kidney.

Preparation of specific antibodies against individual UGTs is not an easy objective since these membrane proteins shares a high degree of amino acid sequence similarity within the family [24]. Considering the issues, we chose a peptide sequence comprising residues 78 to 106 of human UGT2A3, which is free from the predicted N-glycosylation sites, as an antigen to prepare the antibody. Using Western blot analyses with the prepared antibody and recombinant enzymes for each UGT isoform, it was confirmed that the antibody only specifically reacted with UGT2A3. Therefore, we succeeded in the preparation of a specific antibody against UGT2A3 (Fig. 1A).

Substantial UGT2A3 protein expression was detected in the intestine and kidney rather than in the liver (Fig. 1B). This finding implicates a potential role for UGT2A3 in controlling the pharmacokinetics and biological effects of ingested compounds or xenobiotics. In addition, a recent study has suggested, via next-generation sequencing, that UGT2A3 mRNA is upregulated in primary colorectal cancer tissues [25]. Although it is not yet clear how this 
mRNA increase translates into protein and whether the increased UGT2A3 expression accelerates carcinogenesis, that study suggested that UGT2A3 might have an endobiotic function in the gastrointestinal tract. Thus, confirming upregulation of the UGT2A3 protein in cancer tissues and elucidating its function in the development of colorectal cancer are interesting goals that are worth pursuing in the future.

UGTs are membrane-bound enzymes associated with post-translational modifications through the ER. Some UGT isoforms are $N$-linked glycosylated on the ER membrane [26-30]. As shown in Fig. 2A, UGT2A3 also contains potential $N$-glycosylation sites. Using Western blot analysis, it was demonstrated that UGT2A3 is $N$-linked glycosylated (Fig. 2B). The mobility and band patterns of the recombinant UGT2A3 treated with Endo H and PNGase F were different than those of human tissues, which is due to the difference in the $\mathrm{N}$-glycan processing pathways between mammalian and insect species [31]. The hypothesis was proven by the results that showed the mobility and band pattern of UGT2A3 in Huh-7 cells were the same as those in human liver microsomes (Fig. 2B). As previously reported for the UGT1A and UGT2B isoforms $[29,30], N$-linked glycosylation of UGT2A3 would be important for appropriate protein folding and to exert enzymatic function.

We examined the extent of interindividual variability in UGT2A3 expression in a panel of 28 human liver samples. The variability in UGT2A3 mRNA and protein levels was 26-fold and 3-fold, respectively (Figs. 3A and B). A significant positive correlation $(r=0.64, p<$ 0.001) was observed between the UGT2A3 mRNA and protein levels (Fig. 3C), which suggests that transcriptional regulation largely contributes to the variability of the UGT2A3 expression. In the proximal promoter region of UGT2A3, the consensus elements of several transcription factors, including hepatocytes, nuclear factor $1 \alpha$, caudal type homeobox 2 , pregnane $\mathrm{X}$ receptor, and glucocorticoid receptor, were found [9]. However, the regulation mechanisms of UGT2A3 have not previously been studied. In addition, functional analysis of 
single nucleotide polymorphisms in the $U G T 2 A 3$ promoter region has not been performed. It would be of interest to investigate whether the interindividual differences in trans- or cisfactors for these transcription factors as well as post-transcriptional regulation are relevant to the variability of the UGT2A3 expression.

In conclusion, we could successfully prepare a specific monoclonal antibody against the human UGT2A3. Using Western blot analyses, it was demonstrated that UGT2A3 is substantially expressed in the small intestine, kidney and liver, and UGT2A3 is $N$-linked glycosylated. The new antibody was useful in examining the extent of interindividual variability in UGT2A3 protein expression in different human tissues and its cellular localization. We hope that this antibody could trigger and promote structural and functional studies of UGT2A3 and its possible role in health and disease.

\section{Authorship Contributions:}

Participated in research design: Nakajima and Yokoi

Conducted experiments: Gotoh-Saito, Abe, Furukawa, Oda, and Hatakeyama

Contributed new reagents or analytic tools: Hatakeyma and Finel

Performed data analysis: Gotoh-Saito, Abe, and Furukawa

Wrote or contributed to the writing of the manuscript: Gotoh-Saito, Fukami, and Nakajima

\section{Conflict of interest: none}




\section{References}

[1] Miners JO, Mackenzie PI. Drug glucuronidation in humans. Pharmacol Ther 1991;51:347-369.

[2] Kiang TK, Ensom MH, Chang TK. UDP-glucuronosyltransferases and clinical drug-drug interactions. Pharmacol Ther 2005;106:97-132.

[3] Mackenzie PI, Rogers A, Treloar J, Jorgensen BR, Miners JO, Meech R. Identification of UDP glycosyltransferase 3A1 as a UDP N-acetylglucosaminyltransferase. J Biol Chem 2008;283:36205-36210.

[4] Wells PG, Mackenzie PI, Chowdhury JR, Guillemette C, Gregory PA, Ishii Y, et al. Glucuronidation and the UDP-glucuronosyltransferases in health and disease. Drug Metab Dispos 2004;32:281-290.

[5] Guillemette C. Pharmacogenomics of human UDP-glucuronosyltransferase enzymes. Pharmacogenomics J 2003;3:136-158.

[6] Mackenzie PI, Bock KW, Burchell B, Guillemette C, Ikushiro S, Iyanagi T, et al. Nomenclature update for the mammalian UDP glycosyltransferase (UGT) gene superfamily. Pharmacogenet Genomics 2005;15:677-685.

[7] Ritter JK, Chen F, Sheen YY, Tran HM, Kimura S, Yeatman MT, et al. A novel complex locus UGT1 encodes human bilirubin, phenol, and other UDP-glucuronosyltransferase isozymes with identical carboxyl termini. J Biol Chem 1992;267:3257-3261.

[8] Smith SA, Nagalla SR, Andrews DP, Olsen GD. Morphine regulation of a novel diphosphate glucuronosyl-transferase in guinea pig pups following in utero exposure. Mol Genet Metab 1999;68:68-77.

[9] Court MH, Hazarika S, Krishnaswamy S, Finel M, Williams JA. Novel polymorphic human UDP-glucuronosyltransferase 2A3: cloning, functional characterization of enzyme 
variants, comparative tissue expression, and gene induction. Mol Pharmacol 2008;74:744-754.

[10] Sneitz N, Court MH, Zhang X, Laajanen K, Yee KK, Dalton P, et al. Human UDPglucuronosyltransferase UGT2A2: cDNA construction, expression, and functional characterization in comparison with UGT2A1 and UGT2A3. Pharmacogenet Genomics 2009;19:923-934.

[11] Bushey RT, Dluzen DF, Lazarus P. Importance of UDP-glucuronosyltransferases 2A2 and 2A3 in tobacco carcinogen metabolism. Drug Metab Dispos 2013;41:170-179.

[12] Izukawa T, Nakajima M, Fujiwara R, Yamanaka H, Fukami T, Takamiya M, et al. Quantitative analysis of UDP-glucuronosyltransferase (UGT) 1A and UGT2B expression levels in human livers. Drug Metab Dispos 2009;37:1759-1768.

[13] Ohtsuki S, Schaefer O, Kawakami H, Inoue T, Liehner S, Saito A, et al. Simultaneous absolute protein quantification of transporters, cytochromes P450, and UDPglucuronosyltransferases as a novel approach for the characterization of individual human liver: comparison with mRNA levels and activities. Drug Metab Dispos 2012;40:83-92.

[14] Kobayashi Y, Fukami T, Nakajima A, Watanabe A, Nakajima M, Yokoi T. Species differences in tissue distribution and enzyme activities of arylacetamide deacetylase in human, rat, and mouse. Drug Metab Dispos 2012;40:671-679.

[15] Hopp TP, Woods KR. Prediction of protein antigenic determinants from amino acid sequences. Proc Natl Acad Sci USA 1981;78:3824-3828.

[16] Chou PY, Fasman GD. Prediction of protein conformation. Biochemistry 1974;13:222245.

[17] Garnier J, Osguthorpe DJ, Robson B. Analysis of the accuracy and implications of simple methods for predicting the secondary structure of globular proteins. J Mol Biol 1978;120:97-120. 
[18] Emini EA, Hughes JV, Perlow DS, Boger J. Induction of hepatitis A virus: neutralizing antibody by a virus-specific synthetic peptide. J Virol 1985;55:836-839.

[19] Welling GW, Weijer WJ, van der Zee R, Welling-Wester S. Prediction of sequential antigenic regions in proteins. FEBS Lett 1985;188:215-218.

[20] Parker JM, Guo D, Hodges RS. New hydrophilicity scale derived from high-performance liquid chromatography peptide retention data: correlation of predicted surface residues with antigenicity and X-ray-derived accessible sites. Biochemistry 1986;25:5425-5432.

[21] Fujiwara R, Nakajima M, Yamanaka H, Nakamura A, Katoh M, Ikushiro S, et al. Effects of coexpression of UGT1A9 on enzymatic activities of human UGT1A isoforms. Drug Metab Dispos 2007;35:747-757.

[22] Bradford MM. Rapid and sensitive method for the quantitation of microgram quantities of protein utilizing the principle of protein-dye binding. Anal Biochem 1976;72:248-254.

[23] Shirai A, Matsuyama A, Yashiroda Y, Hashimoto A, Kawamura Y, Arai R, Komatsu Y, Horinouchi S, Yoshida M. Global analysis of gel mobility of proteins and its use in target identification. J Biol Chem 2008;283:10745-10752.

[24] Oda S, Fukami T, Yokoi T, Nakajima M. A comprehensive review of UDPglucuronosyltransferase and esterases for drug development. Drug Metab Pharmacokinet 2015;30:30-51.

[25] Wang S, Zhang C, Zhang Z, Qian W, Sun Y, Ji B, et al. Transcriptome analysis in primary colorectal cancer tissues from patients with and without liver metastases using nextgeneration sequencing. Cancer Med 2017;6:1976-1987.

[26] Mackenzie PI. Expression of chimeric cDNAs in cell culture defines a region of UDP glucuronosyltransferase involved in substrate selection. J Biol Chem 1990;265:34323435.

[27] Mackenzie PI. The effect of N-linked glycosylation on the substrate preferences of UDP 
glucuronosyltransferases. Biochem Biophys Res Commun 1990;166:1293-1299.

[28] Barbier O, Girard C, Breton R, Bélanger A, Hum DW. N-glycosylation and residue 96 are involved in the functional properties of UDP-glucuronosyltransferase enzymes. Biochemistry 2000;39:11540-11552.

[29] Nakajima M, Koga T, Sakai H, Yamanaka H, Fujiwara R, Yokoi T. N-Glycosylation plays a role in protein folding of human UGT1A9. Biochem Pharmacol 2010;79:1165-1172.

[30] Nagaoka K, Hanioka N, Ikushiro S, Yamano S, Narimatsu S. The effects of Nglycosylation on the glucuronidation of zidovudine and morphine by UGT2B7 expressed in HEK293 cells. Drug Metab Pharmacokinet 2012;27:388-397.

[31] Shi X and Jarvis DL. Protein N-glycosylation in the baculovirus-insect cell system. Curr Drug Targets 2007;8:1116-1125. 


\section{Figure legends}

Fig. 1. Western blot analysis of UGT2A3 protein using the anti-human UGT2A3 monoclonal antibody. (A) Recombinant UGT1A, UGT2B and UGT2A proteins expressed in baculovirusinfected insect cells. (B) Pooled human microsomes from the liver, kidney, and intestine. (C) Pooled HLM or HLC. (D) Pooled liver (left panel) or intestine (right panel) microsomes from humans, mice and rats. (E) Microsomes from human hepatocellular carcinoma Huh-7 cells and HepG2 cells and human epithelial colorectal adenocarcinoma LS180 cells and Caco-2 cells. HLM, human liver microsomes; HLC, human liver cytosol; MLM, mouse liver microsomes; RLM, rat liver microsomes; HKM, human kidney microsomes; HIM, human intestinal microsomes; MIM, mouse intestinal microsomes; RIM, rat intestinal microsomes; M, marker.

Fig. 2. Western blot analysis of glycosylated human UGT2A3 protein. (A) Schematic representation of potential $\mathrm{N}$ - or $O$-glycosylation sites within the human UGT2A3 protein. (B) Deglycosylation of UGT2A3 protein in HLM, HIM and recombinant UGT2A3 (Sf9) with Endo H (upper panel), PNGase F (middle left panel), and $O$-glycosidase (lower panel). Deglycosylation of UGT2A3 protein in HLM and Huh-7 cells expressing human UGT2A3 with PNGase F (middle right panel). Western blot analysis was performed using the antihuman UGT2A3 monoclonal antibody. The arrowhead and asterisk represent glycosylated and deglycosylated UGT2A3 protein in human liver and intestine microsomes, respectively.

Fig. 3. Interindividual variability of UGT2A3 protein levels in human liver and correlation with UGT2A3 mRNA. (A) Expression levels of UGT2A3 protein in 28 human liver microsomes were determined by Western blot analysis. UGT2A3 protein levels are expressed 
as the levels relative to that of the lowest sample, No. 16. The data are represented as the means \pm SD of three independent determinations. (B) Expression levels of UGT2A3 mRNA in 28 individual human livers were determined by qRT-PCR. UGT2A3 mRNA levels were normalized to GAPDH mRNA levels. The values are expressed as the levels relative to that of the lowest sample, No. 15. The data are represented as the means \pm SD of triplicate determinations. (C) The correlation between the UGT2A3 protein and mRNA levels in 28 individual human livers, using the mean values in Fig. 3A and Fig. 3B. 


\section{Table 1}

Amino acid sequence alignment of the peptide antigen of human UGT2A3 with human UGT isoforms.

\begin{tabular}{|c|c|c|c|c|}
\hline \multirow[t]{2}{*}{ Isoform } & \multirow[t]{2}{*}{ Accession No. } & \multirow[t]{2}{*}{ Sequence } & \multicolumn{2}{|c|}{$\begin{array}{l}\text { Identity with } \\
\text { UGT2A3 (\%) }\end{array}$} \\
\hline & & & $78-106$ & $\begin{array}{c}\text { Full- } \\
\text { Length }\end{array}$ \\
\hline UGT2A3 & Q6UWM9 & ${ }_{78}$ HMPQDRTEENEIFVDLALNVLPGLSTWQS $_{106}$ & & \\
\hline UGT1A1 & P22309 & ${ }_{80}$ PVPFQREDVKESFVSLGHNVFENDSFLQR ${ }_{108}$ & 34 & 45 \\
\hline UGT1A3 & P35503 & AISWTQDEFDRHVLGHTQLYFETEHFLKK & 3 & 41 \\
\hline UGT1A4 & P22310 & ${ }_{81}^{\text {AVPWTQKEFDRVTLGYTQGFFETEHLLKR }}{ }_{109}$ & 7 & 42 \\
\hline UGT1A6 & P19224 & ${ }_{79}$ PVPYDQEELKNRYQSFGNNHFAERSFLTA & 17 & 42 \\
\hline UGT1A7 & Q9HAW7 & ${ }_{78}$ STSYTLEDQDREFMVFADARWTAPLRS-A ${ }_{105}$ & 7 & 43 \\
\hline UGT1A8 & Q9HAW9 & ${ }_{78}$ STSYTLEDLDREFMDFADAQWKAQVRS-L ${ }_{105}$ & 11 & 42 \\
\hline UGT1A9 & O60656 & STSYTLEDLDREFKAFAHAQWKAQVRS-I & 7 & 42 \\
\hline UGT1A10 & Q9HAW8 & STSYTLEDQNREFMVFAHAQWKAQAQS-I & 11 & 42 \\
\hline UGT2A1 & Q9Y4X1 & ${ }_{75}^{18}$ RVPFGKERIEGVIKDFVLTWLENRPSPSTIWRF & 17 & 62 \\
\hline $\mathrm{UGT} 2 \mathrm{~A} 2$ & Q9Y4X1-2 & ${ }_{84}$ PVSYKKSNIDSLIEHMIMLWIDHRPTPLTIWAF & 10 & 63 \\
\hline UGT2B4 & P06133 & ${ }_{78}$ PVSLTKTEFEDI IKQLVKRWA-EL-PKDTFWSY & 25 & 62 \\
\hline UGT2B7 & P16662 & ${ }_{78}$ PTSLTKTELENF IMQQIKRWS-DL-PKDTFWLY & 18 & 59 \\
\hline UGT2B 10 & P36537 & ${ }_{77}$ PTSLTKTEFENI IMQLVKRLS-EI-QKDTFWLP & 18 & 58 \\
\hline UGT2B11 & O75310 & ${ }_{78}$ PTSLTKTEFENI IMQQVKRWS-DI-RKDSFWLY & 18 & 58 \\
\hline UGT2B 15 & P54855 & ${ }_{78}$ PTSLTKNYLEDSLLKILDRWIYGV-SKNTFWSY & 3 & 60 \\
\hline UGT2B 17 & O75795 & ${ }_{78}$ PTSLTKNDLEDFFMKMFDRWTYSI-SKNTFWSY & 7 & 61 \\
\hline UGT2B28 & Q9BY64 & ${ }_{78}$ PTSLTKTEFENI IMQQVKRWS-DI-QKDSFWLY ${ }_{108}$ & 18 & 58 \\
\hline
\end{tabular}

Multiple sequence alignment of human UGT2A3 amino acid residues 78-106 to other human UGT isoforms using Clustal Omega program. Identical amino acid residues from the aligned sequences are shown in gray boxes. 


\section{Table 2}

Amino acid sequence alignment of the peptide antigen of human UGT2A3 with mouse and rat UGT2A3

\begin{tabular}{|c|c|c|c|c|}
\hline \multirow[t]{2}{*}{ Isoform } & \multirow[t]{2}{*}{ Accession No. } & \multirow[t]{2}{*}{ Sequence } & \multicolumn{2}{|c|}{$\begin{array}{c}\text { Identity with human } \\
\text { UGT2A3 }(\%)\end{array}$} \\
\hline & & & $78-106$ & $\begin{array}{c}\text { Full- } \\
\text { Length }\end{array}$ \\
\hline $\begin{array}{c}\text { Human } \\
\text { UGT2A3 }\end{array}$ & Q6UWM9 & ${ }_{78}$ HMPQD---RTEENEIFVDLALNVLPGLSTWQS $_{106}$ & & \\
\hline $\begin{array}{c}\text { Mouse } \\
\text { UGT2A3 }\end{array}$ & Q8BWQ1 & ${ }_{77}$ PLLYEIETAENRLNEIANLAVNVI PNLSLWEA 108 & 28 & 67 \\
\hline $\begin{array}{c}\text { Rat } \\
\text { UGT2A3 }\end{array}$ & D4A147 & ${ }_{77}$ PVLYETEVAENHLNE IVNLAVNVI PNLSLWEA ${ }_{108}$ & 31 & 68 \\
\hline
\end{tabular}

Amino acid residues 78-106 of human UGT2A3 were aligned with the homologous sequence of mouse and rat using Clustal Omega program. Identical amino acid residues from the aligned sequences are shown in gray boxes. 
Figure 1

A
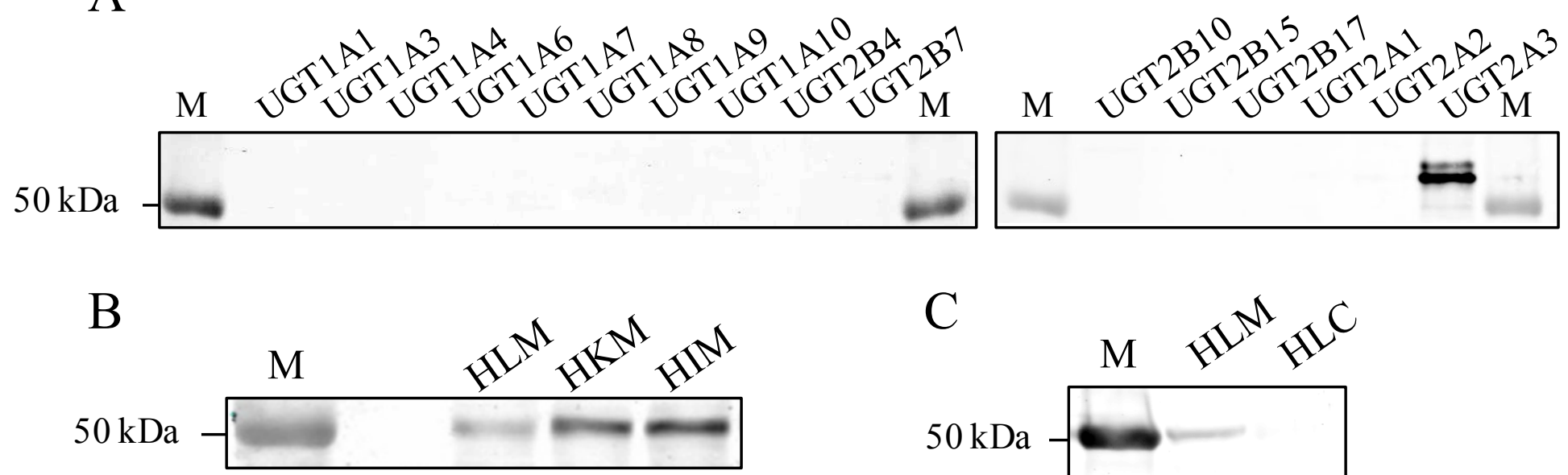

$\mathrm{C}$

D

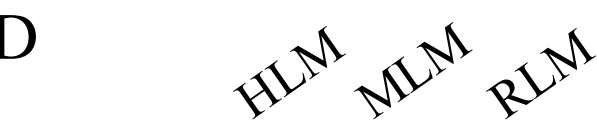

E

$50 \mathrm{kDa}$
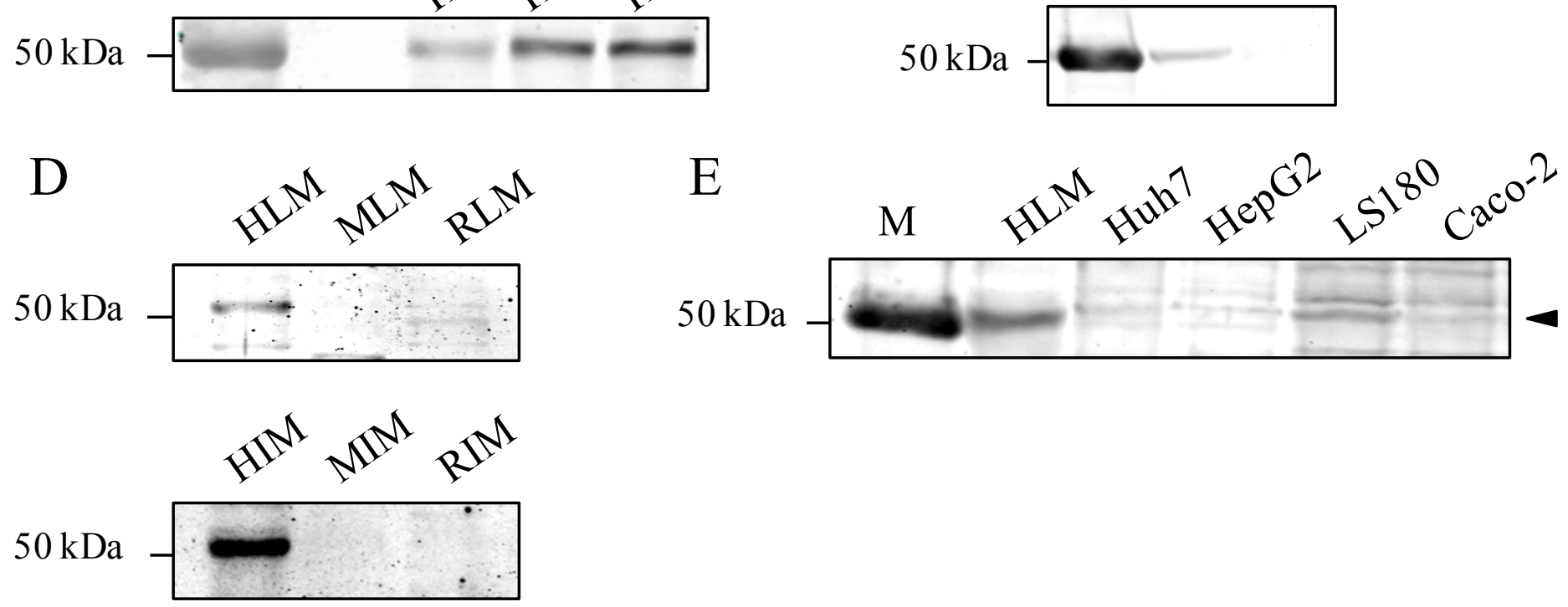
Figure 2

A

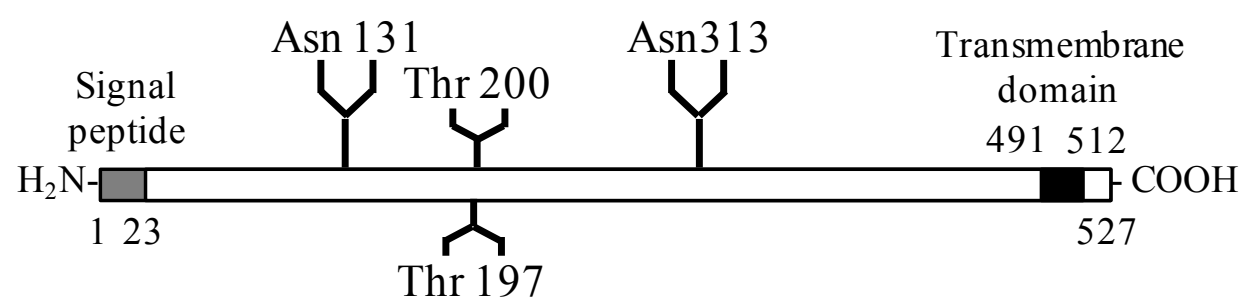

B

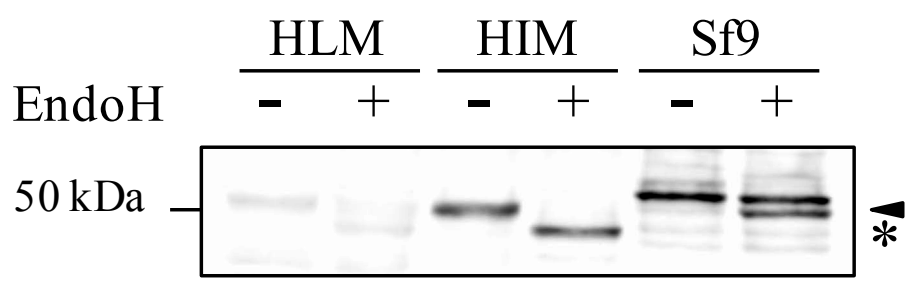

PNGase $\mathrm{F} \quad \frac{\mathrm{HLM}}{-}+\frac{\mathrm{HIM}}{-} \frac{\mathrm{Sf9}}{-\quad+}$

PNGase F $\frac{\text { HLM }}{-\quad+} \frac{\text { Huh-7 2A3 }}{-\quad+}$

$50 \mathrm{kDa}$
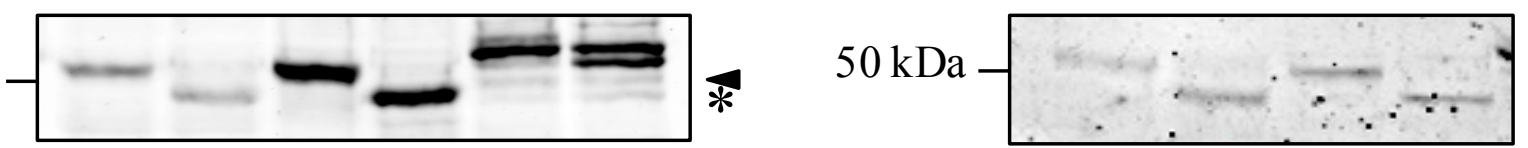

$O$-glycosidase $\frac{\text { HLM }}{-} \frac{\text { HIM }}{-\quad+} \frac{\text { Sf9 }}{-\quad+}$

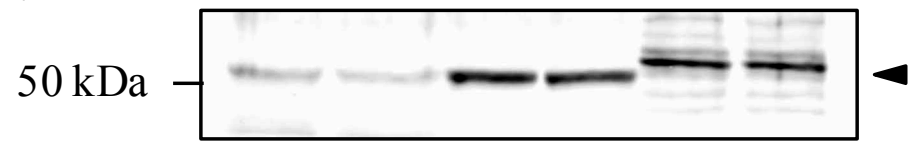


Figure 3

A
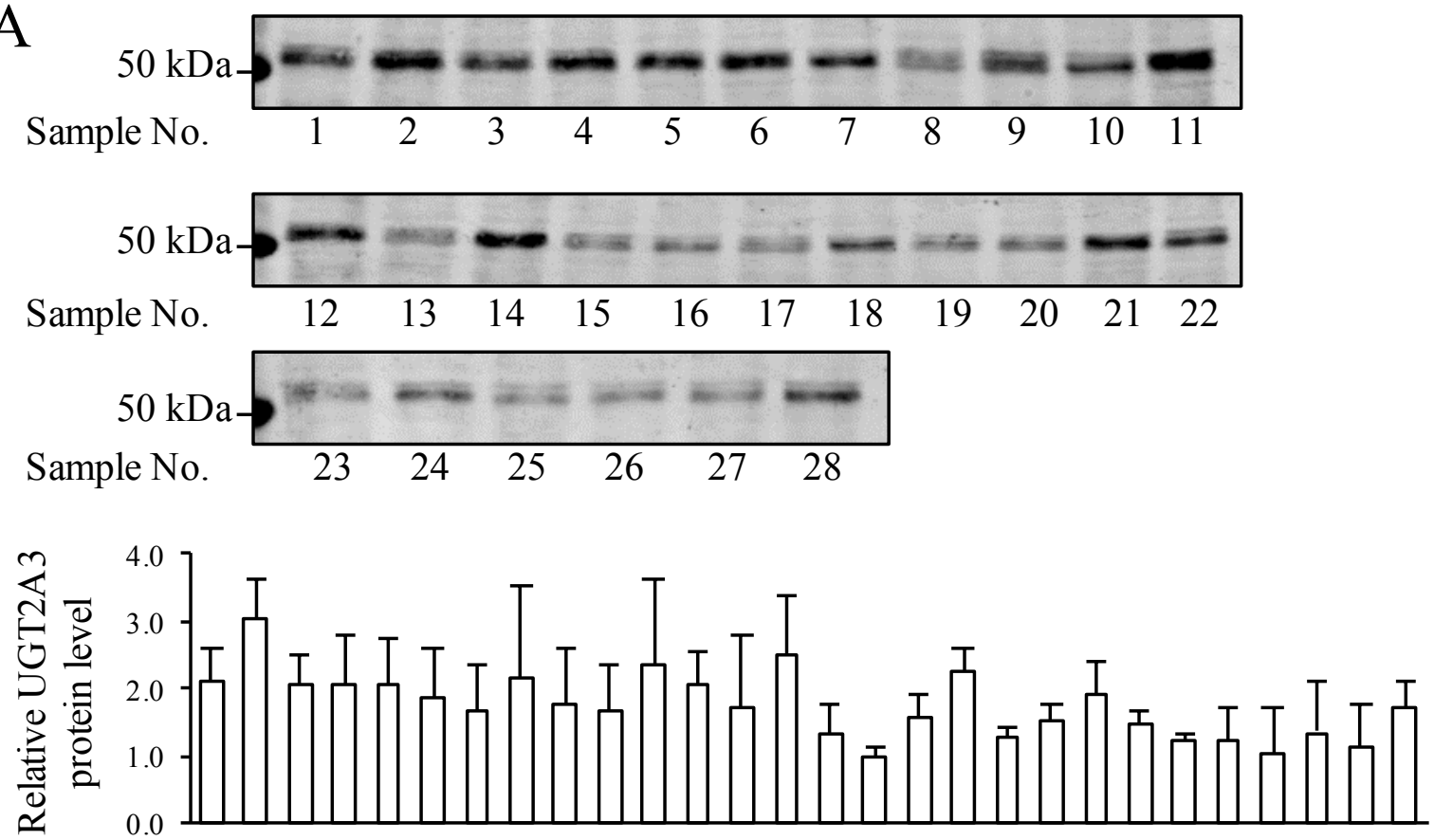

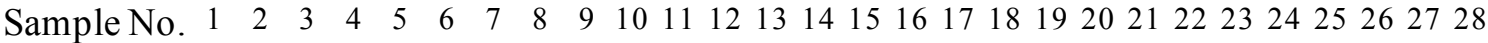

\section{$\mathrm{B}$}

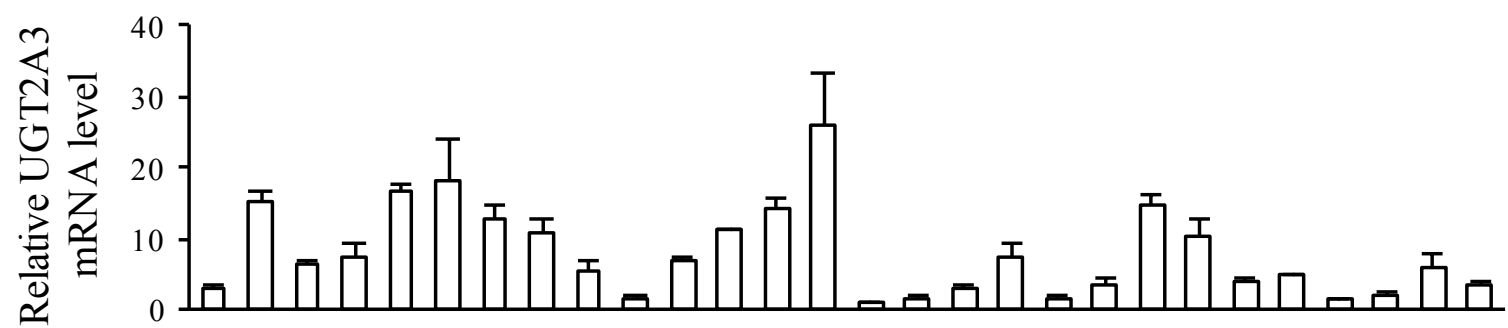

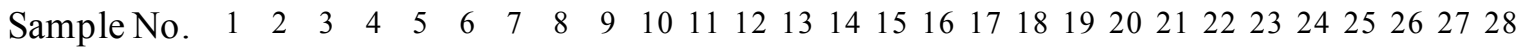

$\mathrm{C}$

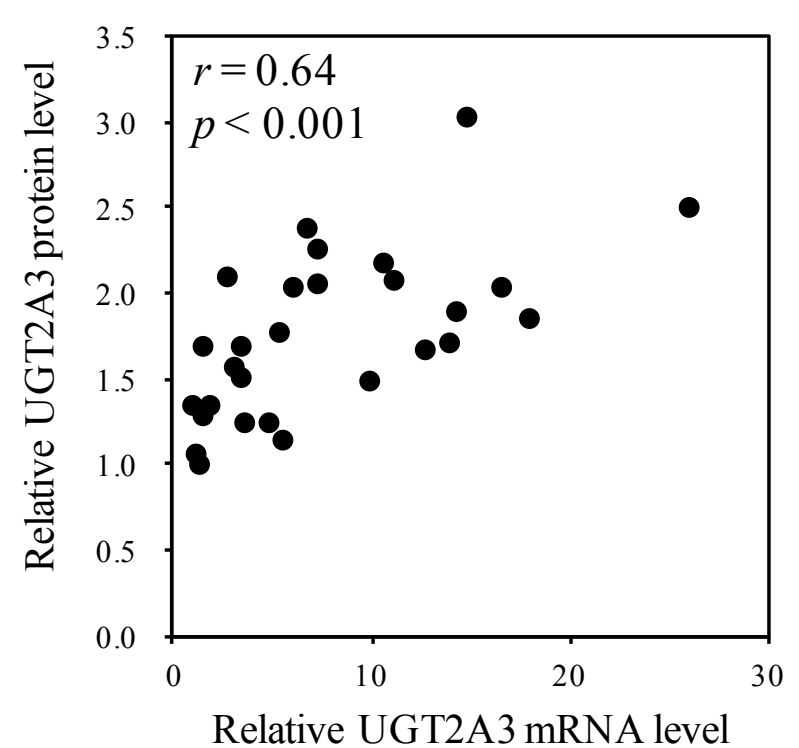

(/GAPDH mRNA level) 